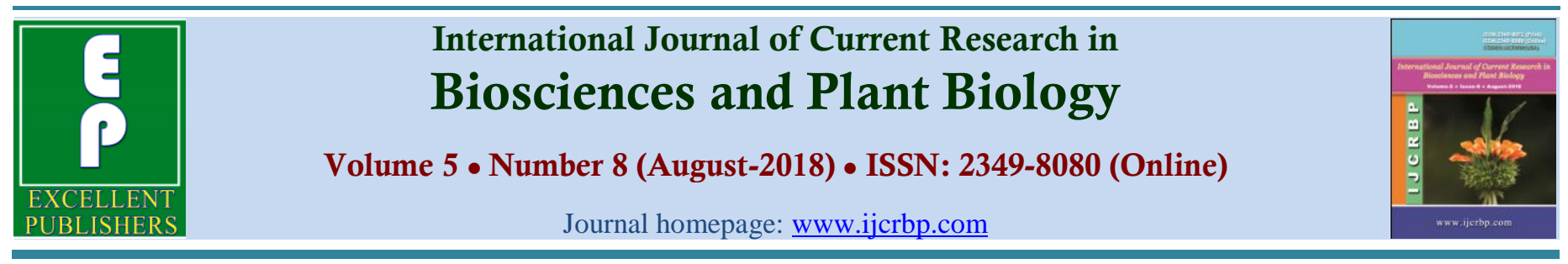

\title{
Antidandruff and Anti-Inflammatory Activity of Piper nigrum Extract against Dandruff Causing Pathogens
}

\author{
N. Deepak ${ }^{*}$, R. Vedayokesh ${ }^{1}$, N. Ganeash ${ }^{1}$ and P. Saminathan ${ }^{2}$
}

1Department of Biotechnology, Jeppiaar Engineering College, Chennai -600 119, Tamil Nadu, India

2Sasham Biologicals Pvt. Ltd Ashok Nagar, Chennai-600 083, Tamil Nadu, India

${ }^{*}$ Corresponding author.

\begin{tabular}{|c|c|}
\hline Article Info & A B S T RACT \\
\hline $\begin{array}{l}\text { Date of Acceptance: } \\
22 \text { July } 2018\end{array}$ & \multirow{4}{*}{$\begin{array}{l}\text { Pepper is known as king of spices belongs to the family Piperaceae. Nearly } 55 \\
\text { phytochemical compounds were present in pepper. Piper nigrum was extracted with } \\
\text { ethyl acetate and chloroform solvents and find its efficacy against dandruff causing } \\
\text { fungus. Dandruff samples were collected and fungus were isolated from dandruff } \\
\text { and identified as Microsporum sp. and Trichophyton sp. Antifungal evaluation of } \\
\text { different extracts of Piper nigrum were tested against dandruff causing isolates. } \\
\text { Among the extracts ethyl acetate showed higher antifungal activity against selected } \\
\text { fungus. Antidandruff and anti-inflammatory activity of ethyl acetate extract of Piper } \\
\text { nigrum were carried out and showed better activity on Microsporum sp. The results } \\
\text { were compared with commercially available shampoos. On comparison, ethyl acetate } \\
\text { extract of Piper nigrum showed excellent inhibitory activity against anti dandruff and } \\
\text { anti-inflammatory. }\end{array}$} \\
\hline $\begin{array}{l}\text { Date of Publication: } \\
06 \text { August } 2018\end{array}$ & \\
\hline Keywords & \\
\hline $\begin{array}{l}\text { Antidandruff activity } \\
\text { Anti-inflammatory activity } \\
\text { Dandruff } \\
\text { Piper nigrum }\end{array}$ & \\
\hline
\end{tabular}

\section{Introduction}

Dandruff was a common scalp disorder (epidermal growth) and the shedding of dead skin cells from scalp. It was associated with seborrheic dermatitis. Keratinocytes play a role in the expression and generation of immunological reactions during dandruff formation. It causes nearly half of the world's population. Probably affects males more than the females. Dandruff was contagious and caused by fungal infection. Dermatophytes were fungi that require keratin for growth. The most common dermatophytes were Microsporum $s p$. and Trichophyton sp. Microsporum was a genus of fungi that causes tinea capitis, tinea corpus, ringworm, and other dermatophytoses. The most common Microsporum species were M. gypseum and $M$. canis. The fungus genus Trichophyton was characterized by the development of both smoothwalled macro- and micro-conidia. The most important significant member of genus were $T$. tonsurans and T. mentagrophytes. 
Most of the traditionally used medicinal plants has got the therapeutic properties and has been used for improving immune system as well as to cure various ailments (Ravichandran et al., 2004). There were many natural and artificial methods were regulated for the control of dandruff. People mostly depend on commercial shampoos, ointments, creams for the control of dandruff. Components present in those products include Zinc Pyrithione, Ketoconazole, and antifungal agents like Clotrimazole, Amphotericim B, Miconazole, Nystatin, etc. (Chandrani et al., 2012). Plant contains natural bio active components like alkaloids, flavonoids, tannins, terpenoids, etc. We choosen white pepper (Piper nigrum) for the present study because of its antifungal and antidandruff properties and had better effectiveness to treat dandruff.

\section{Materials and methods}

\section{Collection of plant material and preparation of plant extract}

The fresh white pepper was collected from local market of Mambalam, Chennai. White pepper was crushed by mixer grinder. Cold extraction method was followed using different solvents (Ethyl acetate and Chloroform) and finally the extracts were filtered through Whatman No.1 filter paper. The crude extract obtained was evaporated and stored at $4^{0} \mathrm{C}$ in refrigerator until use.

\section{Isolation of dandruff causing fungus}

Samples were collected from scalp of 6 persons suffering from dandruff. Collected samples was inoculated into sterile Sabouraud Dextrose Agar (SDA) media and incubated at $32^{\circ} \mathrm{C}$ for 3-5 days.

\section{Identification of dandruff causing fungus}

Microscopic and macroscopic identification were done to specifically identify fungus. Microscopic identification was done by Lactophenol Cotton Blue (LPCB) test. Macroscopic identification was done by morphological, cultural characteristics on SDA.

\section{Dilution of samples}

The commercially available shampoos (ketaconazole and loreal paris), antibiotic, and Piper nigrum were diluted using dimethyl sulfoxide (Naga Padma et al., 2015).

\section{Antifungal assay (Surabhi et al., 2015)}

To check the Minimum Inhibitory Concentration (MIC) of Piper nigrum extracts were made in the range of $1000 \mu \mathrm{g}, 750 \mu \mathrm{g}$ and $500 \mu \mathrm{g}$ samples and their antifungal activity were checked using disc diffusion method. Agar disc diffusion method was done to determine the zone of inhibition of extracts against dandruff causing Trichophyton $s p$. and Microsporum sp.

\section{Antidandruff assay (Sibi et al., 2012)}

Various concentrations of the samples (ethylacetate and chloroform extracts), Loreal Paris and Ketaconazole were diluted in DMSO from the resultant extract to determine its antidandruff activity. Samples were loaded on the sterile discs and placed on the media plates. The plates were incubated at $37^{\circ} \mathrm{C}$ for 3 to 5 days. The zone of inhibition was measured in two directions at right angles to each other by measuring in $\mathrm{mm}$ and recorded against the corresponding concentration.

\section{Anti-inflammatory assay (Gandhisan et al., 1991)}

Fresh blood was collected and mixed with EDTA which acts as an anticoagulant. Samples were centrifuged at $10,000 \mathrm{rpm}$ for $15 \mathrm{~min}$ at room temperature. The supernatants were carefully removed while the packed red blood cell was washed in fresh normal saline $(0.85 \% \mathrm{NaCl})$. The process of washing and centrifugation were repeated five times until the supernatants were clear. This RBC suspension was used for the estimation of anti-inflammatory property.

Different concentration of sample and control were separately mixed with $2 \mathrm{ml}$ of phosphate buffer, $4 \mathrm{ml}$ 
of hyposaline and $0.9 \mathrm{ml}$ of RBC suspension. All the assay mixtures were incubated at $37^{\circ} \mathrm{C}$ for 30 minutes. The supernatant liquid was decanted and the hemoglobin content was estimated by spectrophotometer at $620 \mathrm{~nm}$.

\section{Results}

For the present study was carried out for the period of March 2018- May 2018. Piper nigrum was collected and extracted with two different solvents (ethyl acetate and chloroform) and collect crude extract for further studies. Collected dandruff samples were inoculated on sterile SDA (Sabouraud dextrose agar) plates.

Typical white grayish growth around the plate was indicative of dandruff causing fungus. Dandruff

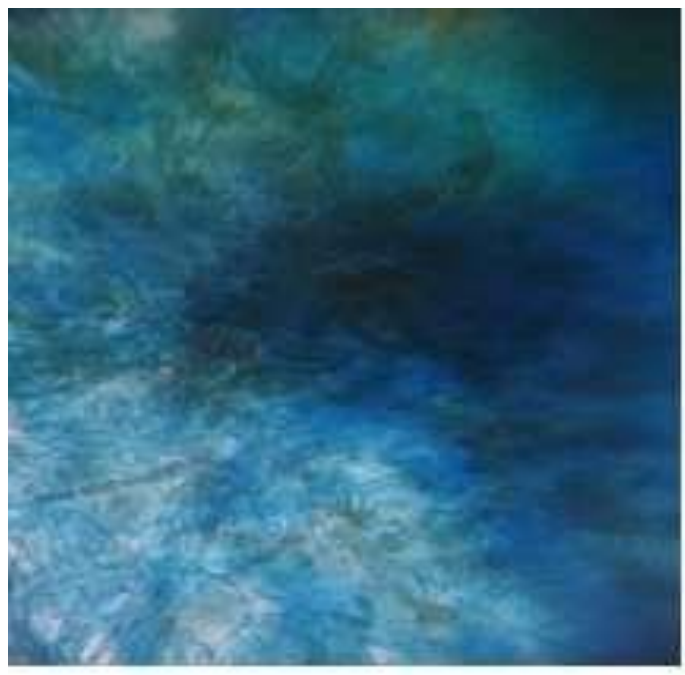

Fig. 1: Microsporum

Total of two solvents (ethyl acetate, chloroform) were used to extract Piper nigrum, commercially available shampoos like Loreal Paris, Ketacanozole and standard Antibiotic (Fluconazole) were screened out for the study of antifungal and antidandruff activity against two different fungal sp. namely Microsporum sp. and Trichophyton sp. isolated from the dandruff samples. Antifungal activity of ethyl acetate and chloroform extracts were represented by concentration vs zone of inhibition in graph 1, 2 and Figs. 3, 4. scrapings gave white colonies around dandruff flakes. Isolated fungus was further used for microbiological analysis.

Isolated fungus were stained using Lactophenol cotton blue stain and observed under $45 \mathrm{X}$ objective (Fig. 1 and Fig. 2). Fig.1 showed that the typical formation of macroconidia with hyaline, multiseptate, variable in form, spindle shaped to ovovate ranging from 20 to $300 \mu \mathrm{m}$ in size. It indicates that the most common Microsporum sp. was isolated and identified.

Fig. 2 showed that the typical formation of macroconidia that borne laterally directly on the hyphae with short pedicels and thin walled ranged from 8 to $50 \mu \mathrm{m}$ in size. It indicates that the most common Trichophyton sp. was isolated and identified.

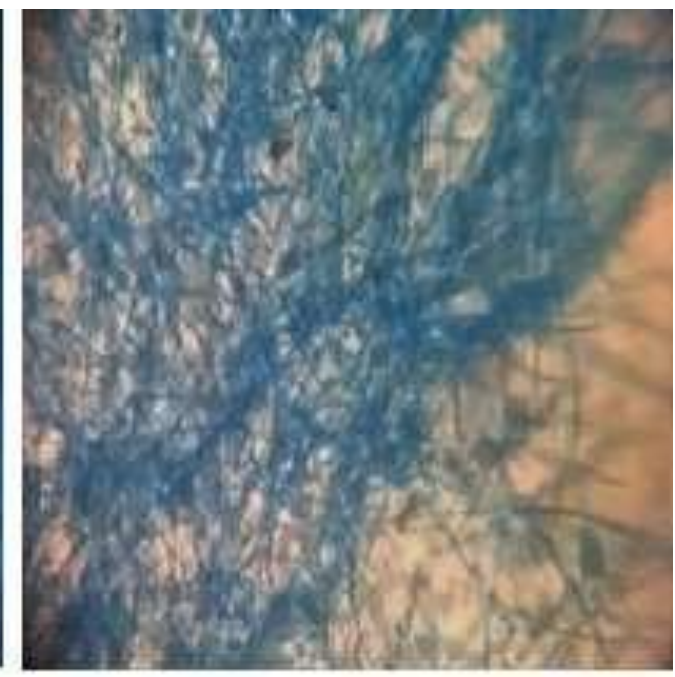

Fig. 2: Trichophyton
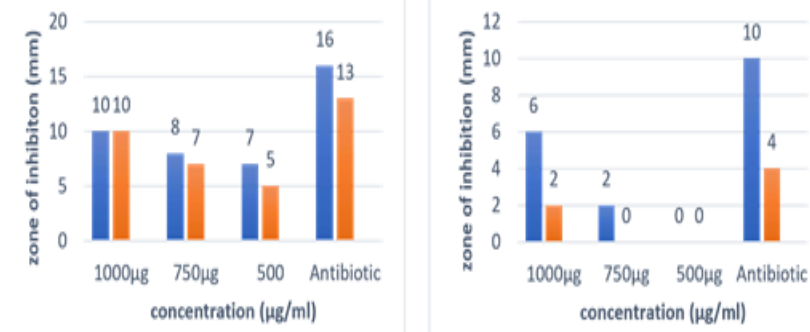

- Microsporum (mm) =Trichophyton(mm)

-Microsporum (mm) $=$ Trichophyton(mm)

Graph 1

Graph 2 
Fig. 3 shows the zone of inhibition in Microsporum sp. (A) and Trichophyton sp. (B) of ethyl acetate extract as antifungal activity.

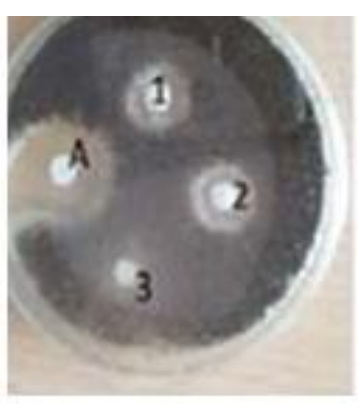

Fig.3 A

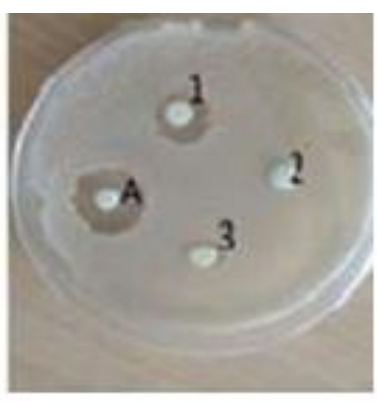

Fig.3 B

Fig. 4 shows the zone of inhibition in Microsporum sp. (A) and Trichophyton sp. (B) of chloroform extract as antifungal activity. Note: 1-1000 $\mu \mathrm{g}, 2-750 \mu \mathrm{g}, 3-500 \mu \mathrm{g}$, A-Antibiotic.

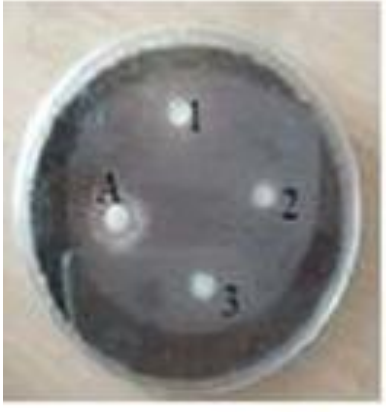

Fig.4 A

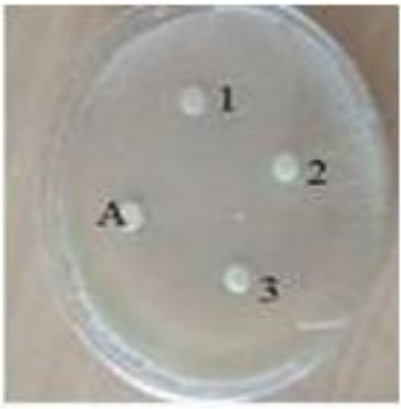

Fig.4 B

From the graph $1 \& 2$ and Figs. $3 \& 4$ we infer that ethyl acetate shows better results for both Microsporum sp. and Trichophyton sp. for antifungal activity. Antidandruff activity of samples was represented by concentration vs zone of inhibition in graph 3.

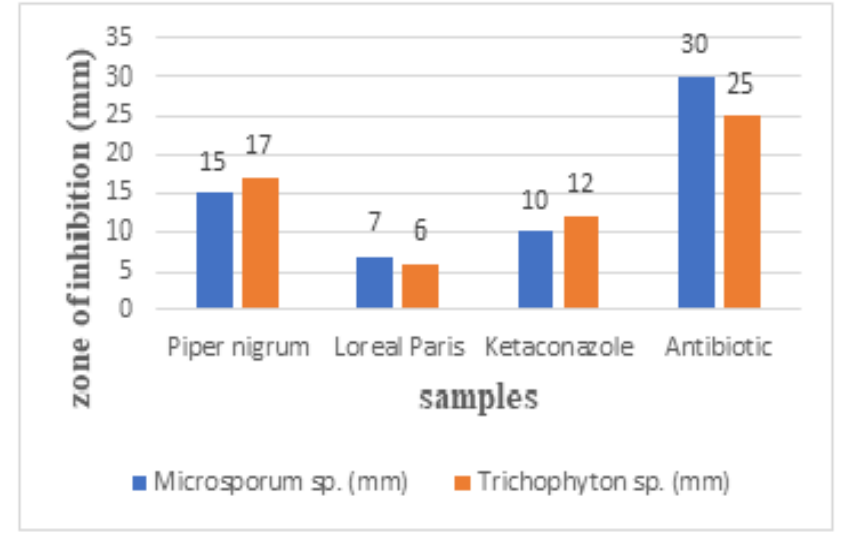

\section{Graph 3}

Fig. 5 shows the zone of inhibition in Microsporum sp. (A) and Trichophyton sp. (B) of samples as antidandruff activity. Note : 1-Piper nigrum, 2-Loreal paris, 3-Ketaconazole, A-Antibiotic (Fluconazole).

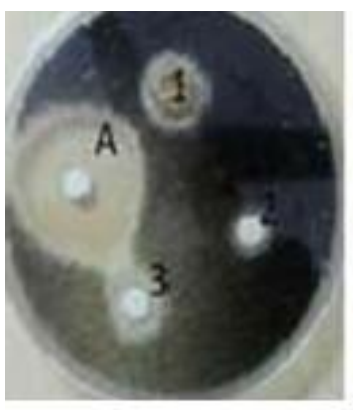

Fig. 5 A

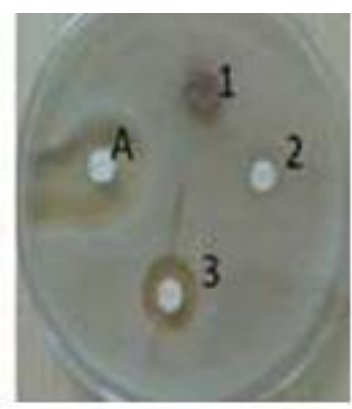

Fig.5 B
From the graph 3 and Fig. 5 we infer that ethyl acetate extract shows better results for Microsporum and Trichophyton as antidandruff activity. 
Anti-inflammatory activity of Piper nigrum represented by concentration vs absorbance in graph 4. From graph 4 we infer that Piper nigrum has better anti-inflammatory activity on ethyl acetate extract.

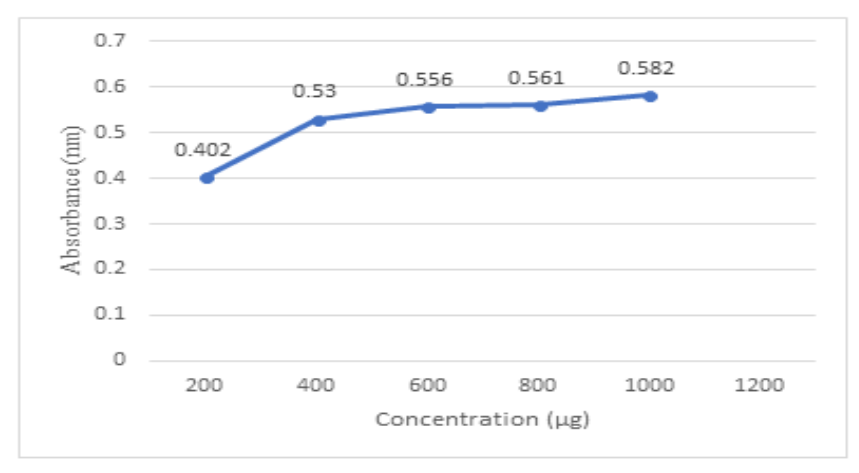

Graph 4

\section{Discussion}

A person's entire body surface continuously sheds dead skin cells and the skin itself sheds every twenty-four days. Dandruff, the shedding of dead skin cells from the scalp at an excessive rate, is the result of the normal growing process of the skin cells of the scalp. The identification of the isolates is done normally by comparing morphological and physiological characteristics (Rasika et al., 2016).

Dandruff may be caused by several different factors, but the exact underlying cause of dandruff is unknown. Dandruff is the visible desquamation of scalp, is the mildest manifestation of seborrheic dermatitis. Common ways to control dandruff is to use agents like imidazoles, selenium sulphide, coal tar and salicylic acid. These shampoos work by slowing down cell turnover and may reduce the number of malassezia (Ravichandran et al., 2004).

During the past few decades, there has been a dramatic increase in the use of natural products in cosmetics. All the antidandruff shampoos had good antifungal activity but there is considerable variation in the potency of their antifungal activity depending on the active compound and its concentration. In the present study the best antidandruff shampoo was Loreal Paris as it contains Zinc pyrithione and arginine. This was followed by Ketoconazole as it contain antifungal compounds like coconut fatty acid diethanolamide and disodium monolauryl ether sulfosuccinate.

The most common cause of dandruff is probably the fungus Malassezia furfur. The plants were selected based upon their usage as traditional medicine for treating dandruff (Mamatha et al., 2016). Most of the plant extracts were showing good antifungal activity almost equivalent to that of commercially available shampoos. Piper nigrum had more antifungal activity and this could be because of their active compound Piperine and also it has antitumour and anticancer activity. Use of natural products is not only cost effective but also negligible side effects. The present study was significant as not only efficient known plant products but also their better efficacies at minimum concentrations could be identified. Herbal drugs or their formulations are viable alternative to synthetic drugs. During the past few decades, there has been a dramatic increase in the use of natural products in cosmetics (Chandrani et al., 2012). The chemicals used for the treatment of dandruff have certain limitations; they are unable to prevent occurrence, which is a common troublesome clinical problem. Most products which are designed to fight dandruff contain zinc pyrithione. Ketaoconazole and ZnPTO based shampoos are used more by the consumers for common dandruff problems. Herbal drugs or their formulations are viable alternative to synthetic drugs.

Further this research work can help make a polyherbal mixture that could be incorporated in hair oil or shampoos for better anti dandruff activity. The excellent antidandruff action of Piper nigrum might have been due to the synergistic antifungal, anti-inflammatory and local immunostimulatory actions of its ingredients, which has been well documented by various research workers (Ravichandran et al., 2004). 


\section{Conflict of interest statement}

Authors declare that they have no conflict of interest.

\section{Acknowledgement}

Authors are very grateful to Sasham Biologicals Pvt. Ltd for the guidance and support to complete this research work.

\section{References}

Chandrani, D., Lubaina, S. Z., Soosama, M., 2012. A review of antifungal effect of plant extract vs chemical substances against Malassezia sp. Int. J. Pharma BioSci. 3(3), 773-780.

Gandhisan, R., Thamaraichelvan, A., Baburaj, S., 1991. Antiinflammatory action of Lannea coromandelica HRBC membrane stabilization. Fitotherapia. 62, 82-83.

Mamatha, P., Sridhar, V., Ramakrishna, R., 2016. Antifungal activity of plant extracts against dandruff causing organism Malassezia furfur. Int. J. Bioassays. 5(11), 5047-5049.

Naga Padma, P., Anuradha, K., Divya, K., 2015. Comparison of potency of antifungal action of dandruff shampoos and different plant extracts. Int. J. Med. Res. Health Sci. 4(2), 327-331.

Nikam, S. R., Khanvilkar, V. V., Jagdale, D. M., Jadhav, A. P., More, S. H., Kadam, V. J., 2013. Evaluation of antibacterial and antifungal activities of marketed anti dandruff shampoos. Indo-Amer. J. Pharmaceut. Res. 3(10), 80978100.

Rasika, M., Parameshwari, S., Sivagurunathan, P., Uma, C., Bhuvaneshwari, M., 2016. Antifungal activity of amla extracts against dandruff causing pathogens. Int. J. Adv. Res. Biol. Sci. 3(1), 209-214.

Ravichandran, G., Shivram Bharadwaj, V., Kolhapure, S. A., 2004. Evaluation of the clinical efficacy and safety of "Antidandruff Shampoo" in the treatment of dandruff. The Antiseptic. 201(1), 5-8.

Sibi, G., Gurmeetkaur, Geeta Devi, Dhananjaya, K., Ravikumar, K. R., Mallesha, H., 2012. Antidandruff activity of Ricinus communis L. leaf extracts. Int. J. Curr. Pharmaceut. Res. 4(3), 74-76.

Surabhi, P., Vaishali, M., 2015. Studies on antifungal activities of certain plant extracts against dandruff causing fungus, Malassezia. Int. J. Curr. Res. Biosci. Plant Biol. 2(7), 206-211.

\section{How to cite this article:}

Deepak, N., Vedayokesh, R., Ganeash, N., Saminathan, P., 2018. Antidandruff and anti-Inflammatory activity of Piper nigrum extract against dandruff causing pathogens. Int. J. Curr. Res. Biosci. Plant Biol. 5(8), 52-57. doi: https://doi.org/10.20546/ijcrbp.2018.508.007 